\title{
Variations in jugular foramen of human skull
}

\author{
Avanish Kumar', Ritu², Md. Jawed Akhtar', Avanindra Kumar ${ }^{3}$ \\ ${ }^{1}$ Department of Anatomy, Indira Gandhi Institute of Medical Sciences, Sheikhpura, Patna, Bihar, India, ${ }^{2}$ Department of Forensic Medicine and \\ Toxicology, Indira Gandhi Institute of Medical Sciences, Sheikhpura, Patna, Bihar, India, ${ }^{3}$ Department of Oral Pathology, Ambedkar Dental \\ College, Patna, Bihar, India
}

\section{A B S T R A C T}

Background: Jugular foramen is one of the foramen at the base of skull lies between the occipital bone and the petrosal portion of the temporal bone. It allows passage of important nervous and vascular elements, such as the glossopharyngeal, vagus accessory nerves, and the internal jugular vein. Glomic tumors, schwannomas, metastatic lesions and infiltrating inflammatory processes are associated with this foramen, which can account for injuries of related structures. Variability in anatomical aspect of jugular foramen has been studied by many workers in different part of the world. Aims \& Objective: To study the variability in shape and size of jugular foramen which has clear cut relationship with size of internal jugular vein and presence or absence of prominent superior bulb. The study is also aimed to confirm the description given in most of the text book of Anatomy that mostly right jugular foramen is larger than left (Figure 1). Materials and Methods: Present study has been designed to study on 68 skulls ( $68 \times 2=136$ foramen). Result: In the study Bilateral presence of dome has been found in $57.35 \%$ of cases whereas bilateral absence in $4.41 \%$ of cases. In $64.7 \%$ of case larger right and in $19.1 \%$ of cases larger left foramen have been observed. In remaining $16.1 \%$ of cases both left and right jugular foramen are almost equal in size. Both unilateral and bilateral complete septation have been observed.

Key words: Jugular foramen, Skull, Septation, Internal jugular vein, Jugular bulb

\section{Access this article online}

Website:

http://nepjol.info/index.php/AJMS

DOI: 10.3126/ajms.v6i2.10940

\section{INTRODUCTION}

In a human jugular (JF) lies between the occipital bone and petrosal portion of temporal bone at the posterior end of petroso occipital structure. It is long and shaped irregularly. Anteriorly it is separated from the inferior carotideal opening by a crest. It is laterally related to the medial face of styloid process covering and separated from the hypoglossal canal by a thin bone bar. Its axis is projected anteromedially.

\section{MATERIALS AND METHODS}

Skull: Study has been performed on dry skull available at anatomy department and department of forensic medicine of different medical and dental college (IGIMS, PMCH, $\mathrm{NMCH}$, Ambedkar dental college) in Patna (India). A total of 68 skulls have been studied. All skulls included in study are devoid of gross malformation.
Vernier caliper: Measurement has been taken by vernier calliper.

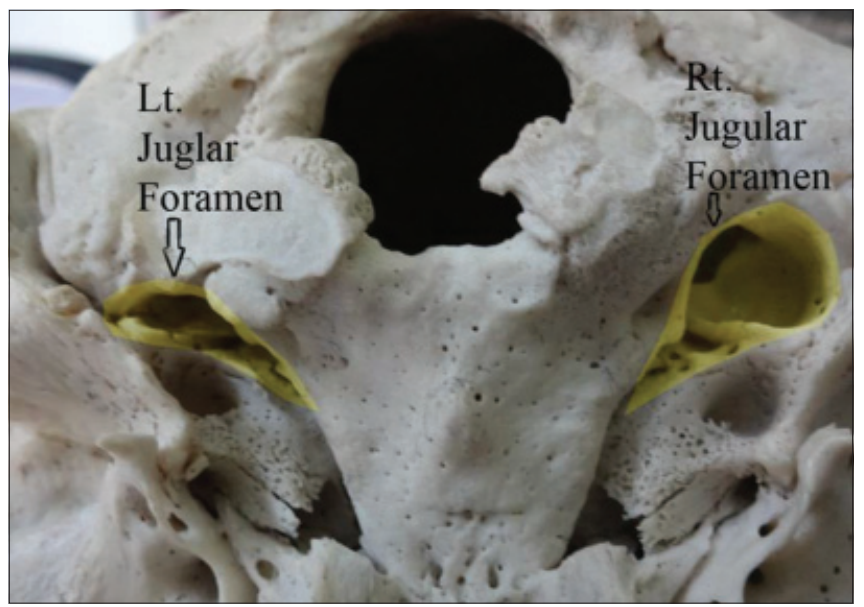

Figure 1: Yellow coloured portion showing difference in size of right and left Jugular foramen 
Antero-posterior diameter of jugular foramen: With the help of vernier calliper the maximum antero-posterior dimension of jugular foramen has been taken.

Presence of dome: By observation.

Septation: Septation in jugular foramen observed.

Collected data compiled into tabular form and compared with studies of other worker.

\section{REVIEW OF LITERATURE}

In different textbooks of anatomy Jugular foramen is described as being divided into three compartments by two marked constrictions; the lateral portion or vascular compartment transmits the internal jugular vein and the meningeal branches of the ascending pharyngeal and occipital arteries, the middle portion or neural compartment transmits the glossopharyngeal, vagus \& spinal accessory nerves; and the medial most transmits the inferior petrosal sinus. The neural and vascular compartments may be divided by a bone projection called the intrajugular process. ${ }^{1-3}$ The foramen presents variations regarding shape, size and laterality for the same skull. According to Gray's Anatomy ${ }^{4}$ lower posterior borders of the jugular foramen are smooth and its posterior border is sharp and notched; sometimes the margins of the notch extend to divide the jugular foramen into two or three compartments. On 300 dried Anatolian skulls from $17^{\text {th }} \& 18^{\text {th }}$ centuries Hatiboglu \& Anil ${ }^{1}$ studied the jugular foramen extensively. Laterality and dominance has also been reported by Wysoki et al; ${ }^{5}$ Berge et al; ${ }^{6}$ Idowu. ${ }^{7}$ The anomalies of the jugular bulb are associated with the JF. The glomic tumors are often in direct contact with structures that cross jugular foramen. Beside this schwannomas, metastatic lesions and infiltrating inflammatory processes can also be related to it.

\section{OBSERVATION}

\section{Anteroposterior measurement (width)}

Anteroposterior Measurement of Jugular foramen in skulls included in the study, varies from $13.5 \mathrm{~mm}$ to 8.5 $\mathrm{mm}$. The mean antroposterior length is $10.6 \mathrm{~mm}$ in right side and $9.2 \mathrm{~mm}$ in left side. It became apparent that at one extreme there is a large foramen with no evidence of complete bony septation but the presence of domed bony roof. The other extreme of variation was complete septation of the part of the foramen which transmit internal jugular vein.

\section{Mediolateral measurement (length)}

In right side mediolateral length of foramina varies between $16.2 \mathrm{~mm}$ to $12 \mathrm{~mm}$ and mean length is 13.6 $\mathrm{mm}$. In left side it varies from $16.5 \mathrm{~mm}$ to $11.9 \mathrm{~mm}$ and mean is $13.9 \mathrm{~mm}$.

Comparison of size between right and left foramina The jugular foramen is larger on the right in $64.7 \%$ of cases, in $19.1 \%$ of cases it is larger in left side whereas in $16.1 \%$ of left and right is equal in size (Table 1).

\section{Dome}

A common variation was the absence of a domed roof, with the bony channel which had been in contact with the internal jugular vein resembling a curved, inverted gutter.

\section{Partial septation}

Partial septations have been observed in $83.17 \%$ in right side and $91.2 \%$ in left side (Table 1). On considering both right and left foramen together $87.5 \%$ of total foramen have partial septations.

\begin{tabular}{|c|c|c|c|c|c|c|c|c|c|c|c|}
\hline \multirow[t]{3}{*}{ Study } & \multicolumn{4}{|c|}{ Presence of dome } & \multicolumn{4}{|c|}{ Septation } & \multicolumn{3}{|c|}{ Size of foramina } \\
\hline & \multirow{2}{*}{$\begin{array}{l}\text { Both } \\
\text { side }\end{array}$} & \multirow{2}{*}{$\begin{array}{l}\text { Right } \\
\text { side }\end{array}$} & \multirow{2}{*}{$\begin{array}{l}\text { Left } \\
\text { side }\end{array}$} & \multirow[t]{2}{*}{ Absent } & \multicolumn{2}{|c|}{ Complete } & \multicolumn{2}{|c|}{ Partial } & \multirow[b]{2}{*}{$R>L$} & \multirow[b]{2}{*}{$R<L$} & \multirow[b]{2}{*}{$R=L$} \\
\hline & & & & & Right & Left & Right & Left & & & \\
\hline \multicolumn{12}{|c|}{ Present study } \\
\hline No & 39 & 20 & 6 & 3 & 11 & 6 & 57 & 62 & 44 & 13 & 11 \\
\hline$\%$ & 57.35 & 29.4 & 8.82 & 4.41 & 16.17 & 8.82 & 83.82 & 91.2 & 64.7 & 19.1 & 16.1 \\
\hline \multicolumn{12}{|c|}{ SM Akram } \\
\hline No & 55 & 00 & 00 & 00 & 42 & 50 & 13 & 5 & 32 & 12 & 11 \\
\hline$\%$ & 100 & 00 & 00 & 00 & 76.3 & 90.9 & 23.6 & 9.1 & 58.2 & 21.8 & 20 \\
\hline \multicolumn{12}{|c|}{ M. M. Patel (2007) } \\
\hline No & 19 & 35 & 13 & 23 & 21 & 16 & 45 & 54 & 55 & 14 & 22 \\
\hline$\%$ & 21 & 38.5 & 14.3 & 25.3 & 23.1 & 17.6 & 49.5 & 59.3 & 60.4 & 15.4 & 24.2 \\
\hline \multicolumn{12}{|c|}{ Sturrock R. R. (1988) } \\
\hline No & 84 & 47 & 10 & 15 & 5 & 5 & 2 & 17 & 107 & 36 & 13 \\
\hline$\%$ & 53.9 & 30.1 & 6.4 & 9.6 & 3.2 & 3.2 & 1.3 & 10.9 & 68.6 & 23.1 & 8.3 \\
\hline
\end{tabular}




\section{DISCUSSION}

The length measurements (latero-medial) and width measurements (anteroposterior) are near to the figures reported by Idowu, ${ }^{7}$ who found the mean length of $13.9 \mathrm{~mm}$ on the right side, and $14.11 \mathrm{~mm}$ on the left side, and the mean width of $10.2 \mathrm{~mm}$ on the right side, and $9.57 \mathrm{~mm}$ on the left side in Nigerian skulls. Hatiboglu and Anil ${ }^{1}$ in Turkish subjects' skulls, and Sturrock (1988), ${ }^{8}$ in a sampling of Roman-British skulls, have also found a larger jugular foramen on the right side, although with a genus-independent analysis.

According to Wysocki et al $^{12}$ results variation can be explained by racial and individual factors. As to the individual factors, these authors mention the significant correlation between the size of the JF and also the hypoglossal channel with skull volume, thus pointing to the significance of cranial capacity for brain venous drainage.

The obtained results regarding complete or partial septum, are far from Sturrock's, ${ }^{8}$ who found complete septation on the right side in $3.2 \%$ of the foramina, and the same figure in foramina of the left side, besides partial septa in 1.3 and $10.9 \%$ on the right side and the left side, respectively.

As to presence of domed bony roof in the jugular foramen the results are almost similar to the result of Sturrock, ${ }^{8}$ who reported $30 \%$ on the right side, and $6 \%$ on the left side, and results are also similar to the ones by Hatiboglu and Anil, ${ }^{1}$ with 36.6 and $4.6 \%$ on the right side and the left side, respectively. Navsa and $\mathrm{Kramer}^{11}$ found a larger volume for the jugular foramen on the right side of female skulls both for the white and the black race. Schelling ${ }^{13}$ reported a significantly larger volume of the jugular foramen on the right side of female skulls. According to Patel ${ }^{9}$ the presence of gutter even in that jugular foramen having had partial dome further suggesting a hypothesis that the size of gutter was inversely proportional to the size of dome for accommodation of superior jugular bulb of internal jugular vein. In Patel's study the dome which is special feature of jugular foramen was present in 38.5\% on right side, in 14.3\% on left side and in $21 \%$ bilaterally. He found the dome to be absent bilaterally in $25.3 \%$ of skulls.

Hatiboglu \& Anil ${ }^{1}$ studied 300 Anatolian skulls from the $17^{\text {th }} \& 18^{\text {th }}$ centuries and found that in $61.6 \%$ the foramen was larger on the right side and in $26 \%$ it was larger on the left side. Sturrock ${ }^{8}$ stated that the size and shape of the jugular foramen is related to the size of the internal jugular vein and the presence or absence of a prominent superior bulb. The difference in size of the two internal jugular veins, according to Sturrock, ${ }^{8}$ is also visible in the human embryo at $23 \mathrm{~mm}$ stage. He also observed in his study that $68.6 \%$ of jugular foramens were larger on right side and $23.1 \%$ were larger on left side and $8.3 \%$ of equal size. MM patel ${ }^{9}$ from saurashtra region (India) reported larger size of foramen in right side in $60.4 \%$ of cases, larger in left side in 15.4 of cases and eual in remaining $24.2 \%$ of cases. $\mathrm{Akram}^{10}$ (from Bangladesh) in his study also found larger foramen in right side in $58.2 \%$, larger foramen in left side in $21.8 \%$ and equal in $20 \%$ of cases. In present study it has been observed that in $64.7 \%$ of cases jugular foramens on right side are larger and in $19.1 \%$ larger on left side, whereas the right and left jugular foramen were found to be of equal size in $16.1 \%$ cases. On comparison of data from above mentioned study it is clear that in percentage of larger foramen in right side varies from $58.2 \%$ to $68.6 \%$.

\section{CONCLUSION}

The large variation of the JF equally reported in various studies is possibly due to constitutional, racial and/or genus factors. Comparison of some parameters was impaired by the scarce data regarding genus and the different approaches to measure this foramen as well. This study supports reported morphometric variations of the JF.

\section{REFERENCES}

1. Hatiboglu MT and Anil A. Structural variations in the jugular foramen of the human skull. Journal of Anatomy 1992; 180: 191-196.

2. Prades JM, Martin $\mathrm{CH}$, Veyretch $\mathrm{B}$, Merzouqui $\mathrm{N}$ and Chelikh L. Anatomic basis of the infratemporal approach of the jugular foramen. Surgical and Radiologic Anatomy 1994; 16:11-20.

3. Williams $P$, Warwick $R$, Dyson $M$ and Bannister L. Gray Anatomia. 37 ed. Rio de Janeiro: Guanabara Koogan, 1995. pp. 329-331. vol. 2.

4. Gray's Anatomy, in: skeletal system; 38 edition, Churchill Livingston e(Edinburgh, London, New York, Philadelphia, Sydney, Toronto.) 1995; pp 574.

5. Wysocki J, Chmielik LP and Gacek W. Variability of magnitude of the human jugular foramen in relation to conditions of the venous outflow after ligation of the internal jugular vein. Otolaryngologia Polska 1999; 53: 173-177.

6. Berge JK and Bergman RA. Variations in size and in symmetry of foramina of the human skull. Clinical Anatomy 2001; 14: 406-413.

7. Idowu OE. The jugular foramen-a morphometric study. Folia Morphologica 2004; 63: 419-422.

8. Sturrock RR. Variations in the structure of the jugular foramen of the human skull. Journal of Anatomy 1988; 160(49): 227- 230.

9. Patel MM and Singel TC. Variations in the structure of the jugular foramen of the human skull in Saurashtra region. J Anat Soc India 2007; 56(2); 34-37. 
10. Akram Hossain SM, Moshadeq Hossain SM, Fakhrul Amin Mohammad Hasannul Banna: Bangladesh Journal of Anatomy july 2012, vol 10 No. 2 pp 45-49.

11. Navsa $\mathrm{N}$ and Kramer $\mathrm{B}$. A quantitative assessment of the jugular foramen. Annals of Anatomy 1998; 180: 269-273.
12. Wysocki J, Reymond J, Skarzynski $\mathrm{H}$ and Wrobel B. The size of selected human skull foramina in relation to skull capacity. Folia Morphologica 2006; 66: 301-308.

13. Schelling $F(1978)$ Die Emissarien des menschlischen Schädels. Anat Anz, 143: 340-382.

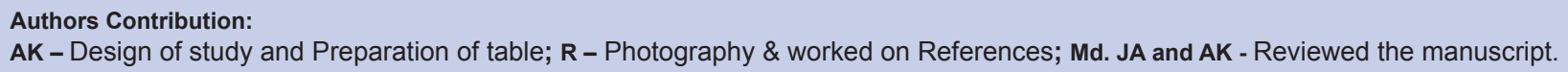

